\title{
Chemical Dimensions of Plastic Wastes and Their Recycling in Environmental Education
}

\author{
Bahattin Aydinli \\ Education Faculty, Kastamonu University, Turkey \\ baydinli@kastamonu.edu.tr
}

Çağrı Avan

Science Teacher, Kastamonu SEKA Primary School, Turkey

cagriavan@gmail.com

\section{Doi:10.5901/jesr.2015.v5n1s1p37}

\begin{abstract}
Environment, energy, recycling, sustainability, various footprints that take attentions of all layers of society, are such a key concepts in last decades. These layers are widespread all over the world in terms of the perspectives of academics, politics, economics, mediatics which all try to manipulate societal life respectively to better position. One of the popular debates is usage of plastics and their supposed environmental pollution. This subject also takes the attention of educators and becomes at least one of the subtitles of environmental education research. While, the governmental municipality which has the key responsibility of these issues, academicians make research about these subjects to activate inner faculties of people. Chemical dimension of environmental issues - along with biology, geography and environmental sciences- helps us to take picture of huge problems. In this study, plastics and their recycling were examined as a chemical dimension of environmental education. And also it is accepted that the attitude of the people is a promising sign and indicator to execute the specified behavior. The attitude sometimes supported on triangles of cognitive, affective, and psychomotor skills which covers than all learning behavior of humans. Here, attitudes of sixth grade students were determined about the plastics and recycling in environment. The previously developed attitude scale was applied to 492 primary school students in Kastamonu province of Turkey. The results were analyzed with statistically and evaluated. The factors of the attitude scale and socioeconomic factors were correlated. Some significant differences related with gender residence type obtained.
\end{abstract}

Keywords: Environmental Education, Plastic, Wastes, Recycling, Attitude Scale, Chemistry

\section{Introduction}

Environment is the area where all living and non living things interact. Environmental education is the regular studies which enable the human beings to make the interaction easier and thus minimizing the possible problems arising from the interaction (Conner\&Sliwka, 2014; Markaki, 2014; Karaarslan et al, 2014). Environment, energy, recycling, sustainability, various footprints take attentions of all layers of society, are such a key concepts in last decades. These layers are widespread all over the world in terms of the perspectives of academics, politics, economics, media which all try to manipulate societal life respectively to better position. One of the popular debates is usage of plastics and their supposed environmental pollution. This subject also takes the attention of educators and becomes at least one of the subtitles of environmental education research (O'Gorman\&Davis, 2013; Rees, 2003; Palliser, 2011).

Both science and social science educators tackle these environmental problems. While, the governmental municipality which has the key responsibility of these issues holding the authority, power, rules and rights, academicians make research about these subjects to activate inner faculties of people. Some of these faculties are relevant and changing according to cultures such as wisdom, conscience, sensitivity, ethics and morals, essence of life, virtues, altruism, pride, guilty, responsibility, rights, duties, citizenship, humanity, esteem, affection, compassion, and charity. These inner faculties can be count and categorized in many ways. So these educational studies tries to take meaningful part in this huge picture and their results have always been evaluated cautiously. To go further in these environmental issues, it seems that the best thing is to collect the positive and meaningful results and making sketches rather than stating contradiction of the previous researches (Haynes, 2009; McClain et al, 2010; Menzel\&Bögeholz, 2009).

Teaching and learning environment is an important issue for sustainable environment. Students who are the basic pillars of society are not only today's citizen but also the citizens of future who are going to shape our future (parents, 
engineer, politician, teacher, unemployed, etc. ) (Varga et al, 2007; Cheong, 2005). The education that the students get about the environmental problems is crucial to prevent environmental problems. Therefore, the data gathered from the preparation of the attitude scale demonstrates students" attitudes about the environmental problems. And the results direct the way of environment education.

Environment and environmental education is a multi- and inter-disciplinary subject. Generally, environmental education is accepted as the main framework of the related subjects. Many different studies appears on this subjects such as sustainable development, environmental literacy, the relation of science-technology-society, and applications of various learning theories such as planned behavior and value-belief-norm theories etc (Oreg\& Katz-Gerro, 2006; Sahin, 2013; Teo\&Tan, 2012). And there are two main streams in human perspectives to nature or environment. One is seeing the humanity as a part of the nature, the other is human is different species then the rest that is the environment is for the purpose of human. The unified third perspective can appear from former two in case of exploiting previously stated inner faculties of human whatever without stating belief or ideology. Accordingly, the findings of solutions to these problems possess great importance.

\subsection{Aim of the Study}

In order to deal with environmental problems and/or to minimize them, the most effective way is raising environmentally conscious and sensitive individuals who should be equipped with necessary knowledge to develop positive attitudes for it. Therefore, education presents crucial importance. Otherwise, damages given to environment cannot be prevented. The basic goal of this study is; to determine concisions level of sixth grade primary school students about the subjects of plastics - wrongly defined previously as a polluter of environment - and their pollution effect, and also environment, recycling and its advantages.

The chemical dimensions of the subjects were tackled in chemical context such as wastes, their disposal and effects to the environment, and recycling concepts along with other dimensions. The chemical dimension of environmental issues - along with biology, geography, environmental and health sciences- helps us to take picture of huge problems. In this study, plastics and recycling were examined as a chemical dimension of environmental education (Cutler\&Moore, 1995). And it is accepted that the attitude of the people is a promising sign and indicator to execute the specified behavior. The attitude sometimes supported on triangles of cognitive, affective, and psychomotor skills which covers than all learning behavior of humans. Also, energy, environment and recycling should be truly understood by the every section of society (science, policy, education, media and people) for sustainable development and inhabitable environment. And these issues should be evaluated within the framework of basic citizenship, which will affect the people's future life more than today and will be a central theme.

Here, the attitude scale which was previously developed by us (Avan et al, 2011) were used where 80 attitude sentences according to 5-point Likert-type scale were prepared and applied to 492 students of $6^{\text {th }}$ grade in the Kastamonu city center of Turkey. It is suitable to give some details about the attitude scale to inform the reader before stating the execution and findings of this study in Table 2. 1. The attitude scale was prepared which demonstrates primary school students" interaction with environment from several perspectives. It is possible to define students" cognitive, affective and psychomotor attitudes about environment, recycling, plastics, and plastic waste. It should be emphasized that affective skill attitudes which is lack in many similar studies, was accommodated. Besides resolving the chemical perspectives, the effects of gender, residence and income were correlated with these mentioned issues. There are several developed attitude scales on environmental education in literature. Our study is complementary to the development of environmental attitude scale in chemistry perspective with concentrating directly on plastic solid waste (Powell et al, 2011; Mobley et al, 2010).

\section{Method}

The patterns of interaction between human and nature is very difficult conflict to be resolved directly. The determinations of attitudes of human towards any subject bears always problem from ancient times till beyond the infinity probably. Here general survey method has been used.

\subsection{Sample and Population}

Here, in this study, attitudes of sixth grade students were determined about the plastics and recycling in environment through using the previously developed attitude scale which was applied to 492 primary school students in Kastamonu 
province of Turkey. The results were analyzed with statistically and evaluated. The factors of the attitude scale and socioeconomic factors were correlated. Some significant differences related with gender residence type obtained. In Tables 2. 1-3 the general data about student gender, residence and income were presented.

Table 2.1: Distribution of Student Genders

\begin{tabular}{ccc}
\hline Gender & Number of Students & $\%$ \\
\hline Male & 247 & 50,2 \\
Female & 245 & 49,8 \\
\hline Total & 492 & 100 \\
\hline
\end{tabular}

Table 2.2: Distribution of Student Residence

\begin{tabular}{ccc}
\hline Residence & Number of Students & $\%$ \\
\hline Family House & 173 & 35,2 \\
Apartment & 219 & 44,5 \\
Apartment Complex (Site) & 100 & 20,3 \\
\hline Total & 492 & 100,0 \\
\hline
\end{tabular}

Table 2.3: Distribution of Student according to their Family Income Annually per capita (Changed into US Dollars according to purchasing power parity of Turkey)

\begin{tabular}{ccc}
\hline Annual Income per capita (\$) & Number of Students & $\%$ \\
\hline Less than 3500 & 196 & 39,8 \\
Between 3500-7500 & 215 & 43,7 \\
More than 7500 & 81 & 16,5 \\
\hline Toplam & 492 & 100,0 \\
\hline
\end{tabular}

\subsection{Data Collecting}

The aforementioned attitude scale consisting of 4 parts was used in order to measure primary school students' attitudes about the recycling, impacts of plastics and plastic wastes on environment. Cognitive, affective, psychomotor skills domains which are the three dimensions of the term attitude were studied separately. In the first part, there are questions to know students' cognition about the issue, in the second part there are questions about the affective approach of students, in the third part there are questions to define the behavioral tendencies, and in the fourth part, there are questions to measure the socio economic conditions. The Cronbach's reliability coefficients of the scale for cognitive, affective and psychomotor domains are $0.854,0.871$ and 0.826 , and there were 3,4 and 5 factors sequentially. The content consistency was determined as sufficient for all scales. As a result, it was found that the scale can be used to define cognitive, affective and psychomotor attitudes.

Table 2.4: Dimensions, Factors, Mean (X), Standard Deviation (SD) and item numbers for each factor of Attitude Scale

\begin{tabular}{lrlrc}
\hline Dimensions of Attitude Scale Factors Phrases of the Factors & X & SD \\
\hline Cognitive Domain & C. 1 & $\begin{array}{l}\text { Understanding the recycling and environment problems } \\
\text { (13 items) }\end{array}$ & 4,48 & 0.35 \\
& C. 2 & Knowing the hazardous effect caused by plastics (6 & 3,19 & 0.85 \\
& items) & Evaluating the plastics as energy resource (3 items) & 3,12 & 0.92 \\
\hline Affective Domain & A. 1 & Wishing to live in clean environment (7 items) & 4,66 & 0.95 \\
& A. 2 & Wishing to reuse the plastics (4 items) & 3,89 & 1.64 \\
& A. 3 & How scattered plastics effects us emotionally (3 items) & 3,98 & 1.82 \\
& A. 4 & Worrying the health effects of reused plastics (3 items) & 3,52 & 1.65 \\
\hline Psychomotor Domain & P. 1 & Attending environment protection (8 items) & 3,23 & 1.06 \\
& P. 2 & Getting use of recycle bin (3 items) & 3,25 & 1.25 \\
& P. 3 & Not throwing garbage away (3 items) & 2,24 & 1.18 \\
& P. 4 & Reusing of plastics (3 items) & 3,37 & 1.18 \\
& P. 5 & Getting use of litter bin (3 items) & 3,30 & 1.08 \\
\hline
\end{tabular}




\section{Findings}

\subsection{The relationship between factors and gender}

The data were analyzed statistically. The relationship between factors and gender were questioned with t-test. There were significant differences $(p<0.05)$ in seven factors and they are given in Table 3. 1. The $\mathbf{X}$ values having positive sign $(+)$ means favorable attitude. So in four factors $\mathrm{C} 1, \mathrm{~A} 1, \mathrm{~A} 3$ and P5 male students are positive and in the rest three factors C2, A4 and P. 5 female students show positive behavior.

Table 3.1. The t-test results of the relationship between factors and gender

\begin{tabular}{|c|c|c|c|c|c|c|c|}
\hline Factors & Gender & $\mathbf{N}$ & $\mathrm{X}$ & SS & Sd & $\mathrm{t}$ & $p$ \\
\hline \multirow[t]{2}{*}{ C. 1 Understanding the recycling and environment problems } & Female & 245 & 0,16 & 0,84 & \multirow{2}{*}{490} & \multirow{2}{*}{3,58} & \multirow{2}{*}{0,001} \\
\hline & Male & 247 & $-0,159$ & 1,12 & & & \\
\hline \multirow[t]{2}{*}{ C. 2 Knowing the hazardous effect caused by plastics } & Female & 245 & $-0,153$ & 0,98 & \multirow{2}{*}{490} & \multirow{2}{*}{3,43} & \multirow{2}{*}{0,001} \\
\hline & Male & 247 & 0,152 & 0,99 & & & \\
\hline \multirow[t]{2}{*}{ A. 1 Wishing to live in clean environment } & Female & 245 & 0,231 & 0,88 & \multirow{2}{*}{490} & \multirow{2}{*}{5,26} & \multirow{2}{*}{0,001} \\
\hline & Male & 247 & $-0,23$ & 1,05 & & & \\
\hline \multirow[t]{2}{*}{ A. 3 How scattered plastics effects us emotionally } & Female & 245 & 0,14 & 0,97 & \multirow{2}{*}{490} & \multirow{2}{*}{3,15} & \multirow{2}{*}{0,002} \\
\hline & Male & 247 & $-0,14$ & 1,01 & & & \\
\hline \multirow[t]{2}{*}{ A. 4 Worrying the health effects of reused plastics } & Female & 245 & $-0,18$ & 1,01 & \multirow{2}{*}{490} & \multirow{2}{*}{3,95} & \multirow{2}{*}{0,001} \\
\hline & Male & 247 & 0,17 & 0,95 & & & \\
\hline \multirow{2}{*}{ P. 3 Not throwing garbage away } & Female & 245 & $-0,209$ & 0,87 & \multirow{2}{*}{490} & \multirow{2}{*}{4,72} & \multirow{2}{*}{0,001} \\
\hline & Male & 247 & 0,207 & 1,08 & & & \\
\hline \multirow[t]{2}{*}{ P. 5 Getting use of litter bin } & Female & 245 & 0,095 & 0,97 & \multirow{2}{*}{490} & \multirow{2}{*}{2,099} & \multirow{2}{*}{0,036} \\
\hline & Male & 247 & $-0,094$ & 1,03 & & & \\
\hline
\end{tabular}

\subsection{The relation between factors and residence}

Also, the relation between factors and residence were investigated and significant difference $(p<0,05)$ between C1 factor and residence was obtained and thus Post-Hoc test was used as Gabriel test to explain the differences in group. The results are shown in Table 3. 2 and 3. 3. Accordingly, two significant differences obtained 1. between family house and apartment, and 2. family house and site. That is residents in site and apartments are more conscious probably due to population density of the habitat which is more sensitive garbage scattering and pollution.

Table 3.2: The anova analysis results of $\mathrm{C} 1$ factor with residence

\begin{tabular}{lccccc}
\hline Source of Variance & Sum of Squares & sd & Mean of the Squares & F & P \\
\hline Inter-groups & 10,307 & 2 & 5,154 & 5,243 & 0,006 \\
Within-groups & 480,693 & 489 & 0,983 & & \\
Total & 491,000 & 491 & & & \\
\hline
\end{tabular}

Table 3.3: The Gabriel test results of $\mathrm{C} 1$ factor with residence

\begin{tabular}{llccc}
\hline Residence & Residence & Mean Difference & Standard Deviation & $(\mathrm{p})$ \\
\hline \multirow{2}{*}{ Family House } & Apartment & $-0,275^{*}$ & 0,1 & 0,019 \\
& Site & $-0,348^{*}$ & 0,12 & 0,015 \\
\hline \multirow{2}{*}{ Apartment } & Family House & $0,275^{\star}$ & 0,1 & 0,019 \\
& Site & $-0,073$ & 0,12 & 0,9 \\
\hline \multirow{2}{*}{ Site } & Family House & $0,348^{\star}$ & 0,12 & 0,015 \\
& Apartment & 0,073 & 0,12 & 0,9 \\
\hline
\end{tabular}




\subsection{The relation between factors and income}

Additionally, Also, the relation between factors and income were investigated and significant difference $(p<0,05)$ between $\mathrm{C} 1$ factor and income was obtained and thus Post-Hoc test was used as Gabriel test to explain the differences in group. The results are shown in Table 3. 4 and 3. 5. Accordingly, two significant differences obtained between middle income group with both low income and high income groups. That is middle income group is showing more environmentally behavior than higher income group.

Table 3.4: The anova analysis results of $\mathrm{C} 1$ factor with income

\begin{tabular}{cccccc}
\hline Source of Variance & Sum of Squares & sd & Mean of the Squares & $\mathbf{F}$ & $\mathbf{P}$ \\
\hline Inter-groups & 8,963 & 2 & 4,482 & 4,546 & 0,01 \\
Within-groups & 482,037 & 489 & 0,986 & & \\
Total & 491,000 & 491 & & & \\
\hline
\end{tabular}

Table 3.5: The Gabriel test results of $\mathrm{C} 1$ factor with income

\begin{tabular}{llccc}
\hline Annual Income per capita (\$) & Annual Income per capita (\$) & Mean Difference & Standard Deviation & (p) \\
\hline \multirow{2}{*}{ Less than 3500 } & Between 3500-7500 & $-0,268^{*}$ & 0,098 & 0,02 \\
& More than 7500 & $-0,293$ & 0,131 & 0,07 \\
\hline \multirow{2}{*}{ Between 3500-7500 } & Less than 3500 & $0,268^{*}$ & 0,098 & 0,02 \\
& More than 7500 & $-0,249$ & 0,129 & 0,99 \\
\hline \multirow{2}{*}{ More than 7500 } & Less than 3500 & 0,293 & 0,131 & 0,07 \\
& Between 3500-7500 & 0,025 & 0,129 & 0,99 \\
\hline
\end{tabular}

\section{Results and Discussion}

The inspections of results reveals that in seven of twelve (7/12) factors showed significant differences between gender which can be attributed to gender theory and/or environmental factors on genders which attributes differences inborn or the effect of external environment in growth of child between genders. And also C1 factor shows significant differences with residence and income. This may stem from consistency of $\mathrm{C} 1$ factor which has 13 sentences as total 13 items. The other factors have limited number item sentences and thus not revealed any significant factor.

Social aspects of male students come forth about more than female students on environmental issues. Also, positive attitudes of male students come to the fore for the following issues; waste recycling, re-use and use of it as an energy source. Therefore it can be concluded that they perceive these subjects in economically. However, female students put forward more importance on the environmental pollution, the clarity of living space and attendance to cleaning workshops. The similar results were cited in the literature. The main reason for this observation can be the Turkish family structure and culture that while female family members are struggling for housework, male family members are engaging in earning money.

If the results are examined for the case of residence type, students living in apartments and site complexes have more positive attitudes than any types of single houses. Peoples living in apartments and sites have to store their wastes in finite living space, whereas, peoples in single houses can somehow scatter wastes randomly in environment due to relatively infinite living space. Therefore, it can be assumed that peoples living in apartments and sites takes care more to the environment.

Middle-income students have more positive attitudes in environmental issues. They have positive attitudes in cognitive and affective skill domains, but problems lie in transforming these into behavior i. e. , psychomotor skill domain. This negative situation may stem from the students' family that they may not have enough awareness in these issues. Because these type of habits were learned in the family and it is difficult to these conventionality in schools.

The environmental issues are newly taken into account and citizens (all segments of the population) do not have enough knowledge in this area. Environmental issues must be re-handled by taking into accounts many factors, and also primary school books and contents should be revised. The teachers specialized in environment should be trained. And all segments of population should be taken into environmental education programme of course, first of all, educators, officers, workers and farmers. The wrong choice made now may totally perish our future.

The significant differences were obtained with gender within which it can be claimed that the female students 
handles this subject in social manner, whereas, males perceives in economical perspectives. This may be stemmed from Turkish culture and family structure where the separation and perception and responsibilities are strictly divided and defined. Also, the significant differences were observed according to residence where students living in building complex were exhibited more affirmative attitudes.

The topics in this study were grasped well by students cognitively, but the trouble lies in transforming knowledge into behavior and action. The correlations between socioeconomic and attitude scale factors were revealed. Shortly, this type of studies should be elaborated and kept on with developing new programmes and spreading in public.

\section{References}

Avan, Ç. , Aydınlı, B. , Bakar, F. , Alboğa, Y. (2011). Preparing Attitude Scale to Define Students' Attitudes about Environment, Recycling, Plastic and Plastic Waste. International Electronic Journal of Environmental Education, 1 (3), 179-191.

Cheong, I. P. -A. (2005). Educating Pre-Service Teachers for a Sustainable Environment. Asia-Pacific Journal of Teacher Education, 33 (1), $97-110$

Conner, L. \& Sliwka, A. (2014). Implications of Research on Effective Learning Environments for Initial Teacher Education. European Journal of Education, 49 (2), 165-177.

Cutler, A. \& Moore, S. (1995). Consumer Education: The Key to Successful Plastics Recycling. Resource Recycling, 14 (5), 29-30.

Haynes, C. C. (2009). Schools of Conscience. Educational Leadership, 66 (8), 6-13.

Karaarslan, G. ; Sungur, S. ; Ertepinar, H. (2014). Developing Preservice Science Teachers' Self-Determined Motivation toward Environment through Environmental Activities. International Journal of Environmental and Science Education, 9, (1), 1-19.

Markaki, V. (2014). Environmental Education through Inquiry and Technology.

Science Education International, 25 (1), 86-92.

McClain, L. ; Ylimaki, R. ; Ford, M. P. (2010). Sustaining the Heart of Education: Finding Space for Wisdom and Compassion. International Journal of Children's Spirituality, 15 (4), 307-316.

Menzel, S. , Bögeholz, Susanne. (2009). Values, beliefs and norms that foster Chilean and

German pupils' commitment to protect biodiversity. International Journal of Environmental and Science Education, 5 (1), 31-49.

Mobley, C. ; Vagias, W. M. ; DeWard, S. L. (2010). Exploring Additional Determinants of Environmentally Responsible Behavior: The Influence of Environmental Literature and Environmental Attitudes. Environment and Behavior, 42 (4), 420-447.

O'Gorman, Lyndal \& Davis, Julie (2013) Ecological footprinting: its potential as a tool for change in preservice teacher education. Environmental Education Research, 19 (6), 779-791.

Oreg, S. \& Katz-Gerro, T. (2006). Predicting Proenvironmental Behavior Cross-Nationally: Values, the Theory of Planned Behavior, and Value-Belief-Norm Theory. Environment and Behavior, 38, $462-483$.

Palliser, J. (2011). Green Science: Revisiting Recycling. Science Scope, 35 (3), 14-17.

Powell, R. B. ; Stern, M. J. ; Krohn, B. D. ; Ardoin, N. (2011). Development and Validation of Scales to Measure Environmental Responsibility, Character Development, and Attitudes toward School. Environmental Education Research, 17 (1), 91-111.

Rees, W. E. (2003). Impeding Sustainability? The Ecological Footprint of Higher Education. Planning for Higher Education, 88-98

Sahin, E. (2013). Predictors of Turkish Elementary Teacher Candidates' Energy Conservation Behaviors: An Approach on Value-BeliefNorm Theory. International Journal of Environmental and Science Education, 8 (2), 269-283.

Teo, T \& Tan, L. (2012). The Theory of Planned Behavior (TPB) and Pre-Service Teachers' Technology Acceptance: A Validation Study Using Structural Equation Modeling. Journal of Technology and Teacher Education, 20 (1), 89-104.

Varga, A. ; Koszo, M. F. ; Mayer, M. ; Sleurs, W. (2007). Developing Teacher Competences for Education for Sustainable Development through Reflection: The Environment and School Initiatives Approach. Journal of Education for Teaching: International Research and Pedagogy, 33 (2), 241-256. 